Fixed Point Theory, 18(2017), No. 1, 57-68

http://www.math.ubbcluj.ro/ ${ }_{\text {nodeacj/sfptcj.html }}$

\title{
SPLIT FEASIBILITY AND FIXED POINT PROBLEMS FOR ASYMPTOTICALLY $k$-STRICT PSEUDO-CONTRACTIVE MAPPINGS IN INTERMEDIATE SENSE
}

\author{
QAMRUL HASAN ANSARI*, AISHA REHAN** AND JEN-CHIH YAO*** \\ * Department of Mathematics, Aligarh Muslim University, Aligarh 202002, India \\ and Department of Mathematics, King Fahd University of Petroleum and Minerals, Dhahran, \\ Saudi Arabia, \\ E-mail: qhansari@gmail.com \\ ** Department of Mathematics, Aligarh Muslim University, Aligarh 202002, India \\ E-mail: aishashaheen370@gmail.com \\ *** Center for General Education, China Medical University, Taichung, Taiwan 40402, R.O.C; and \\ Department of Mathematics, King Abdulaziz University, P.O. Box 80203, Jeddah 21589, Saudi \\ Arabia \\ E-mail: yaojc@mail.cmu.edu.tw
}

\begin{abstract}
This paper deals with the weak convergence of the relaxed extragradient method with regularization for computing a common element of the solution set of split feasibility problem and the fixed points set of a asymptotically $k$-strict pseudo-contractive mapping in intermediate sense. A numerical example is provided to illustrate the main result of this paper.

Key Words and Phrases: Split feasibility problems; Fixed point problems; Relaxed extragradient method; Asymptotically $k$-strict pseudo-contractive mappings in intermediate sense; Convergence analysis.
\end{abstract}

2010 Mathematics Subject Classification: 49J40, 49J52, 47J20, 47H10.

\section{REFERENCES}

[1] Q.H. Ansari, Topics in Nonlinear Analysis and Optimization, World Education, Delhi, 2012.

[2] Q.H. Ansari, C.S. Lalitha, M. Mehta, Generalized Convexity, Nonsmooth Variational Inequalities, and Nonsmooth Optimization, CRC Press, Taylor \& Francis Group, Boca Raton, London, New York, 2014.

[3] Q.H. Ansari, A. Rehan, Split feasibility and fixed point problems, Nonlinear Analysis: Approximation Theory, Optimization and Applications, (Ed. Q.H. Ansari), Birkhäuser, Springer, New Delhi, Heidelberg, New York, London, 2014, 281-322.

[4] C. Byrne, Block iterative methods for image reconstruction form projections, IEEE Trans. Image. Process., 5(1996), 96-103.

[5] C. Byrne, Iterative oblique projection onto convex subsets and the split feasibility problem, Inverse Probl., 18(2002), 441-453.

[6] C. Byrne, A unified treatment of some iterative algorithms in signal processing and image reconstruction, Inverse Probl., 20(2004), 103-120.

[7] L.-C. Ceng, Q.H. Ansari, J.-C. Yao, An extragradient method for solving split feasibility and fixed point problems, Computat. Math. Appl., 64(2012), 633-642. 
[8] L.-C. Ceng, Q.H. Ansari, J.-C. Yao, Relaxed extragradient method for solving split feasibility and fixed point problem, Nonlinear Anal., 75(2012), 2116-2125.

[9] L.-C. Ceng, Q.H. Ansari, J.-C. Yao, Mann type iterative methods for finding a common solution of split feasibility and fixed point problems, Positivity, 16(2012), 471-495.

[10] Y. Censor, T. Bortfeld, B. Martin, A. Trofimov, A unified approach for inversion problems in intensity-modulated radiation therapy, Phys. Med. Biol., 51(2006), 2353-2365.

[11] J. Deepho, P. Kumam, Split feasibility and fixed-point problems for asymptotically quasinonexpansive, Fixed Point Theory Appl., 2013(2013), Article ID 322.

[12] K. Geobel, W.A. Kirk, Topics in Metric Fixed Point Theory. Cambridge Studies in Advanced Mathematics, 28, Cambridge University Press, Cambridge, 1990.

[13] T.H. Kim, H.-K. Xu, Strong convergence of modified Mann iterations for asymptotically strict pseudo-contraction, Nonlinear Anal., 68(2008), 2828-2836.

[14] M.O. Osilike, S.C. Aniagbosor, Weak and strong convergence theorems for fixed points of asymptotically nonexpansive mappings, Math. Computat. Model., 32(2000), 1181-1191.

[15] Z. Opial, Weak convergence of the sequence of successive approximations for nonexpansive mappings, Bull. Amer. Math. Soc., 73(1967), 591-597.

[16] L. Qihou, Iterative sequence for asymptotically quasi-nonexpanslve mappings, J. Math. Anal. Appl., 259(2001), 1-7.

[17] R.T. Rockafellar, On the maximality of sums of nonlinear monotone operators, Trans. Amer. Math. Soc., 149(1970), 75-88.

[18] D.R. Sahu, H.-K. Xu, J.-C. Yao, Asymptotically strict pseudo-contractive mappings in the intermediate sense, Nonlinear Anal., 70(2009), 3502-3511,

[19] H.-K. Xu, Iterative methods for the split feasibility problem in infinite-dimensional Hilbert spaces, Inverse Probl., 26(2010), Article ID 105018, 17 pp.

Received: December 12, 2014; Accepted: May 28, 2015. 